\title{
The role of interleukin-33 in chronic rhinosinusitis
}

- Additional material is published online only. To view please visit the journal online (http://dx.doi.org/10.1136/ thoraxjnl-2016-208772)

\section{'Department of} Otorhinolaryngology-Head and Neck Surgery, Chuncheon Sacred Heart Hospital and

Nano-Bio Regenerative Medical Institute, Hallym University College of Medicine, Chuncheon, Republic of Korea ${ }^{2}$ Clinical Mucosal Immunology Study Group, Seoul, Republic of Korea

${ }^{3}$ Department of Otorhinolaryngology-Head and Neck Surgery, Boramae Medical Center, Seoul National University College of Medicine, Seoul, Korea

${ }^{4}$ Department of

Otorhinolaryngology, Dankook University College of Medicine Chonan, Republic of Korea ${ }^{5}$ Beckman Laser Institute Korea, Dankook University College of Medicine, Chonan, Republic of Korea

${ }^{6}$ Division of Allergy-Immunology Department of Internal Medicine, University of South Florida College of Medicine, Tampa, Florida, USA DDepartment of Biostatistics, Boramae Medical Center, Seoul, Republic of Korea

\section{Correspondence to} Dae Woo Kim, Department of Otorhinolaryngology-Head and Neck Surgery, Boramae Medical Center, Seoul Nationa University College of Medicine, 425 Shindaebang 2-dong, Dongjak-gu, Seoul 156-707 Korea; kicubi@daum.net

Received 13 April 2016 Revised 30 October 2016 Accepted 31 October 2016 Published Online First 24 November 2016

\section{SLinked}

- http://dx.doi.org/10.1136/ thoraxjnl-2016-209655

\section{CrossMark}

To cite: Kim D-K, Jin HR Eun KM, et al. Thorax 2017:72:635-645.

\author{
Dong-Kyu Kim, ${ }^{1,2}$ Hong Ryul Jin, ${ }^{3}$ Kyoung Mi Eun, ${ }^{3}$ Ji-Hun Mo, ${ }^{2,4,5}$ Seong H Cho, ${ }^{6}$ \\ Sohee Oh, ${ }^{7}$ David Cho, ${ }^{3}$ Dae Woo Kim ${ }^{2,3}$
}

ABSTRACT

Rationale Interleukin (IL)-33, a new member of the IL-1 family, is constitutively expressed in epithelial tissues and lymphoid organs and plays an important role in the pathogenesis of allergic disease. However, the role of IL-33 in chronic rhinosinusitis with nasal polyps (CRSwNP) remains unclear.

Objective To investigate the role of IL-33 in the pathophysiology of CRSwNP.

Methods We investigated IL-33 expression and its cellular origins in the nasal polyps (NPs) of human subjects by immunohistochemistry (IHC), quantitative reverse transcription PCR (qRT-PCR), and multiplex cytokine assays. Correlations between IL-33 expression and other inflammatory markers were also explored. To investigate the role of IL-33 in CRSWNP, anti-IL-33 antibody was used in a murine model of CRS.

Results Uncinate process tissues from control (19), CRSsNP (61), CRSwNP (69) and NP tissues (71) were used in this study. Increased expression of IL-33 mRNA and protein in patients with CRSWNP compared with controls was observed. The concentration of IL-33 protein in CRSwNP was positively correlated with the number of neutrophils and the expression of several Th1 and Th17 inflammatory markers, including interferon (IFN)- $\gamma$, IL-1 $\beta$, tumour necrosis factor (TNF)- $\alpha$, IL-17A, IL-22, and various markers for neutrophil recruitment. However, protein levels of IL- 5 and quantity of eosinophils were inversely correlated with levels of IL-33. The expression of tissue inhibitor of metalloproteinase (TIMP)-1 was negatively correlated with IL-33 protein levels, while the expression of matrix metalloproteinase (MMP)-2 and MMP-9 was positively correlated with IL33 protein levels. In animal studies, IL-33 expression was upregulated in the CRSWNP group compared with controls. Anti-IL-33 treatment reduced the thickness of oedematous mucosa, subepithelial collagen deposition, and infiltration of neutrophils, but infiltration of eosinophils was not reduced. This treatment also inhibited the expression of neutrophilic inflammatory cytokines, but not IL-4. In addition, the expression of intracellular adhesion molecule 1, vascular adhesion molecule 1 and CXCL-2 in the nasal mucosa was suppressed in mice treated with anti-IL-33 antibody. Conclusions Our data suggest a role for IL-33 in the pathogenesis of CRSwNP via neutrophil recruitment. Therefore, anti-IL-33 may provide a new treatment strategy to target infiltrating neutrophils in CRSwNP.

\section{INTRODUCTION}

Interleukin (IL)-33 is a novel member of the IL-1 superfamily and constitutively expressed at high levels in epithelial cells from human and mouse

\section{Key messages}

What is the key question?

- Does interleukin (IL)-33 play an important role in the development of chronic rhinosinusitis with nasal polyp (CRSwNP)?

What is the bottom line?

- IL-33 expression is elevated in nasal tissues of patients with CRSwNP, and expression of this cytokine is associated with Th1/Th17 cytokines, neutrophil recruitment and remodelling proteins.

\section{Why read on?}

- IL-33 is one of the crucial mediators of pathogenesis in CRSwNP through neutrophil recruitment, and a promising target for the treatment of patients with CRSwNP.

tissues during homeostasis. ${ }^{1-3}$ IL-33 is produced by various types of immune cells such as macrophages and dendritic cells and by non-immune cells, including endothelial, epithelial, and smooth muscle cells. ${ }^{4}$ Biologically active full-length IL-33 can be released extracellularly by necrotic cells after tissue damage caused by airborne allergens, viruses and air pollutants. ${ }^{45}$ After release, IL-33 subsequently serves as an 'alarmin' by triggering inflammatory response by activating various types of immune cells, including eosinophils, Th2 cells and innate lymphoid cells type 2 (ILC2s). ${ }^{6} 7$ Thus, this cytokine is considered to play a crucial role in Th2 inflammation. However, besides promoting the Th2 response, IL-33 plays a diverse role in various inflammatory diseases. Some evidence suggests a role for IL-33 in recruiting neutrophils by increased production of the chemokine ligand 1 (CXCL-1) and preventing the downregulation of the receptor for CXCR-2. ${ }^{8}$ Other research shows that IL-33 can amplify macrophage polarisation towards an alternatively activated phenotype and can enhance production of tumour necrosis factor (TNF)- $\alpha .{ }^{10}{ }^{11}$ Moreover, in various rheumatological diseases, IL-33 appears to have proinflammatory effects, such as activating synovial fibroblasts and mast cells, and inducing neutrophil migration. $^{12-14}$

Chronic rhinosinusitis (CRS) is one of the most common chronic rhinological diseases and results in a decreased quality of life for affected people. ${ }^{15} 16$ CRS is characterised by accumulation of inflammatory cells and marked tissue 
remodelling, and is currently divided into two clinical phenotypes: CRS without nasal polyps (CRSsNP) and CRS with nasal polyps (CRSwNP), based primarily on endoscopic findings. ${ }^{17}$ CRSwNP often show higher disease severity and risk of recurrence compared with CRSsNP. ${ }^{18}$

More recently, expression of IL-33 and its receptor ST2 was also investigated in patients with CRS, ${ }^{19-21}$ and two of these studies reported elevated expression of ST2, ${ }^{19} 20$ implying that the IL-33/ST2 pathway may function in nasal polypogenesis. Despite these findings, the specific role of IL-33 in the pathophysiology of patients with CRSwNP still remains unclear. Therefore, in this study we investigated the expression of IL-33 and the relationship between IL-33 and other inflammatory markers in sinonasal tissues from patients with CRSwNP. We also evaluated the therapeutic potential of blocking IL-33 in a murine model of CRS.

\section{METHODS}

Detailed methods can be found in the online supplementary data (http://www.thorax.bmj.com).

\section{Patients and tissue samples}

Sinonasal and polyp tissues were obtained from patients with CRS during routine functional endoscopic sinus surgery. All patients provided written informed consent for study participation, and this study was approved by the institutional review board of Seoul National University Hospital, Boramae Medical Center. The diagnosis of CRS was based on personal history, physical examination, nasal endoscopy and CT findings of the sinuses according to the 2012 European position paper on rhinosinusitis and nasal polyps (EPOS) guidelines. ${ }^{17}$ Exclusion criteria were as follows: (1) younger than 18 years of age; (2) prior treatment with antibiotics, systemic or topical corticosteroids, or other immune-modulating drugs for 4 weeks before surgery; and (3) unilateral rhinosinusitis, antrochoanal polyp, allergic fungal sinusitis, cystic fibrosis or immotile ciliary disease (see online supplementary figure S1). Control tissues were obtained during other rhinological surgeries, such as skull base, lacrimal duct or orbital decompression surgery, from patients without any sinonasal diseases. In this study, we obtained uncinate process (UP) tissue from controls and patients with CRS, including those with CRSsNP or CRSwNP. Each sample obtained was divided into three parts: one third was fixed in 10\% formaldehyde and embedded in paraffin for histological analysis, another third was immediately frozen and stored at $-80^{\circ} \mathrm{C}$ for subsequent isolation of mRNA, and the final third of the tissue was submersed in $1 \mathrm{~mL}$ phosphate-buffered saline (PBS) supplemented with $0.05 \%$ Tween-20 (Sigma-Aldrich, St Louis, Missouri, USA) and 1\% PIC (Sigma-Aldrich) per $0.1 \mathrm{~g}$ of tissue. This tissue was homogenised with a mechanical homogeniser at $1000 \mathrm{rpm}$ for $5 \mathrm{~min}$ on ice. After homogenisation, the suspensions were centrifuged at $3000 \mathrm{rpm}$ for $10 \mathrm{~min}$ at $4^{\circ} \mathrm{C}$. The supernatants were separated and stored at $-80^{\circ} \mathrm{C}$ for further analysis of cytokines and other inflammatory mediators. ${ }^{22}$ The atopic status of study patients was evaluated using the ImmunoCAP assay (Phadia, Uppsala, Sweden), which detects IgE antibodies against common aeroallergens (house dust mites, moulds, trees, weeds, grass, and animal dander). Patients were considered atopic if the allergen-specific IgE level was greater than $0.35 \mathrm{KU} / \mathrm{L} .{ }^{23}$ A diagnosis of asthma was performed by an allergist based on medical history and lung function analysis, including methacholine challenge tests. Nasal polyps (NPs) were classified into two groups: eosinophilic NP, which was defined as having an eosinophil count of more than $10 \%$ of the inflammatory cell population, and non-eosinophilic NP, which did not fulfil this criterion. ${ }^{24}$ Additional information and details of the subjects' characteristics are listed in table 1 .

\section{Immunohistochemistry}

Immunohistochemistry (IHC) staining was performed with Polink-2, polymerised horseradish peroxidase (HRP), and broad DAB Detection System (Golden Bridge International Labs., Washington, USA). Paraffin sections were treated with $3 \%$ hydrogen peroxide $\left(\mathrm{H}_{2} \mathrm{O}_{2}\right)$ and then incubated with primary antibodies and biotinylated secondary antibodies. The numbers of positive cells in epithelia, glands and submucosa were determined in the densest part of the tissue in five high-power fields (HPF; $\times 400)$ by two independent observers, and average values were determined. Detailed IHC procedures are described in the Methods section in the Online Repository at http://www.thorax. bmj.com.

\section{Quantitative real-time PCR for inflammatory markers}

The mRNA levels in UP and NP tissues were evaluated using quantitative real-time (qRT)-PCR analysis as previously described. ${ }^{24}$ Detailed qRT-PCR conditions are described in the Methods section in the Online Repository (http://www.thorax. bmj.com).

\section{Measurement of cytokine protein levels in tissue homogenates}

The protein concentrations for tissue extracts were determined using the Pierce $660 \mathrm{~nm}$ Protein Assay Kit (Thermo Scientific Inc, New York, USA). Samples were thawed at room temperature and vortexed to ensure a well mixed sample. Multiplex cytokine analysis kits (IL-1 $\beta$, IL-5, IL-17A, IL-22, IL-33, interferon (IFN)- $\gamma$, CXCL- 8 , MPO, GRO- $\alpha$, GRO- $\beta$, intercellular adhesion molecule (ICAM)-1, matrix metalloproteinase (MMP)-2, MMP-9, tissue inhibitor of metalloproteinase (TIMP)-1 and TNF- $\alpha$ ) were obtained from R\&D systems (Cat. No. LMSAHM) and data were collected using Luminex 100 (Luminex, Austin, Texas, USA). Data analysis was performed using the MasterPlex QT V.2.0 (MiraiBio, Alameda, California, USA). All assays were run in duplicate according to the manufacturers' protocol. Sensitivity of each cytokine is as follows: IL-1 $\beta$ $(0.8 \mathrm{pg} / \mathrm{mL}), \quad$ IL-5 $\quad(0.5 \mathrm{pg} / \mathrm{mL}), \quad$ IL-17A $\quad(1.8 \mathrm{pg} / \mathrm{mL}), \quad$ IL-22 $(11.7 \mathrm{pg} / \mathrm{mL}), \mathrm{IL}-33(1.8 \mathrm{pg} / \mathrm{mL}), \mathrm{IFN}-\gamma(0.4 \mathrm{pg} / \mathrm{mL})$, CXCL-8 $(1.8 \mathrm{pg} / \mathrm{mL})$, MPO $(20.4 \mathrm{pg} / \mathrm{mL})$, GRO- $\alpha(5.3 \mathrm{pg} / \mathrm{mL})$, GRO- $\beta$ $(7.86 \mathrm{pg} / \mathrm{mL}), \quad$ ICAM-1 $(87.9 \mathrm{pg} / \mathrm{mL}), \quad$ MMP-2 $(108 \mathrm{pg} / \mathrm{mL})$,

Table 1 Patient characteristics and study methodology

\begin{tabular}{lcccc}
\hline & Control & CRSsNP & \multicolumn{1}{l}{ CRSwNP } \\
\cline { 5 - 5 } Total no. of subjects & $\mathrm{N}=19$ & $\mathrm{~N}=61$ & $\mathrm{~N}=69$ & $\mathrm{~N}=71$ \\
\hline Tissue used & $\mathrm{UP}$ & $\mathrm{UP}$ & $\mathrm{UP}$ & $\mathrm{NP}$ \\
Age (years), mean (SD) & $45(19)$ & $49(13)$ & $48(14)$ & $49(14)$ \\
Atopy, N (\%) & $6(31)$ & $18(29)$ & $27(39)$ & $29(40)$ \\
Asthma, N (\%) & 0 & $3(5)$ & $5(7)$ & $5(7)$ \\
Lund-Mackay CT score & $0(0)$ & $8.9(5.3)$ & $15.3(6.1)$ & $15.6(5.1)$ \\
Methodologies used & & & & \\
$\quad$ Tissue IHC & $9(47 \%)$ & $25(41 \%)$ & $24(35 \%)$ & $58(82 \%)$ \\
$\quad$ Tissue mRNA & $17(89 \%)$ & $61(100 \%)$ & $69(100 \%)$ & $71(100 \%)$ \\
$\quad$ Homogenate ELISA & $9(47 \%)$ & $7(11 \%)$ & $27(39 \%)$ & $36(51 \%)$
\end{tabular}

CRSsNP, chronic rhinosinusitis without nasal polyps; CRSwNP, chronic rhinosinusitis with nasal polyps; IHC, immunohistochemistry; NP, nasal polyp; UP, uncinate process. 
MMP-9 (13.6 pg/mL), TIMP-1 (3.42 pg/mL) and TNF- $\alpha$ $(1.2 \mathrm{pg} / \mathrm{mL})$. All the protein levels in the tissue homogenate were normalised to the concentration of total protein $(\mathrm{mg} / \mathrm{mL})$.

\section{Murine model of chronic rhinosinusitis}

All animal experiments were approved by the IACUC of Boramae Medical Center and were performed under strict governmental and international guidelines on animal experimentation. Nasal polypoid lesions in mice were induced according to a previously established protocol, ${ }^{25}$ which has been confirmed by multiple studies. ${ }^{26-28}$ Thirty-two female BALB/c mice (4 weeks old, 20-25 g) were divided into three groups: PBS-treated (PBS, $n=10$ ), CRS model group (CRS, $n=12$ ), and CRS model group treated with anti-IL-33 (R\&D systems, Minneapolis, Minnesota, USA; CRS $+\alpha I L-33, n=10)$. Detailed animal experiments are described in the Methods section in the Online Repository at http://www.thorax.bmj.com.

\section{Cytokines from nasal lavage fluid in murine model}

Nasal lavage was performed as previously described. ${ }^{29}$ After partial tracheal resection under deep anaesthesia, a micropipette was inserted into the posterior choana through the tracheal opening in the direction of the upper airway. Each nasal cavity was gently perfused with $200 \mu \mathrm{L}$ PBS, and the fluid from the nostril was collected and centrifuged. Supernatants were stored at $-80^{\circ} \mathrm{C}$. Levels of IFN- $\gamma$, IL-4, IL-17A and transforming growth factor (TGF)- $\beta 1$ in the nasal lavage fluids were measured using ELISA kits purchased from BioLegend (San Diego, California, USA). The lower detection limits of these ELISA kits were $8 \mathrm{pg} / \mathrm{mL}$ for IFN- $\gamma, 0.5 \mathrm{pg} / \mathrm{mL}$ for IL-4, $2.7 \mathrm{pg} / \mathrm{mL}$ for IL-17A and $2.3 \mathrm{pg} / \mathrm{mL}$ for TGF- $\beta 1$.

\section{Statistical analysis}

Statistical analyses were performed using GraphPad Prism software V.6.0 (GraphPad software Inc, La Jolla, California, USA). In this study, the Kruskal-Wallis test and the Mann-Whitney U test with a two-tailed test for unpaired comparisons were used. For comparisons among groups, the Kruskal-Wallis test was used to establish the significant difference (human study groups: Control-UP, CRSsNP-UP, CRSwNP-UP, NP; animal study groups: Control, POLYP, POLYP $+\alpha I L-33)$. The MannWhitney $\mathrm{U}$ test was then used for between-group comparisons with Bonferroni adjustment for multiple comparisons to
Figure 1 Expression of interleukin (IL)-33 in nasal tissues according to the different types of chronic rhinosinusitis. Comparison of IL-33 expression within the uncinate process (UP) tissues from control subjects, patients with chronic rhinosinusitis without nasal polyps (CRSsNP), and patients with chronic rhinosinusitis with nasal polyps (CRSwNP), and from nasal polyp (NP) tissues from patients with CRSwNP. (A) Protein levels of IL-33 among groups and (B and C) Difference between eosinophilic and non-eosinophilic NPs in the protein and mRNA levels. IL-33 expression was compared between UP and NP tissues in (D) non-eosinophilic CRSwNP (NE-NP) and (E) eosinophilic CRSwNP (E-NP). (F) Number of HNE-positive and $(G)$ EMBP-positive inflammatory cells was counted from five of the densest areas (high power field; $\times 400$ ) and those were compared with the concentration of IL-33 homogenated. IL-33 antibody from R\&D (accession \#095760) was used in multiplex cytokine analysis. ${ }^{*} p<0.05,{ }^{* *} p<0.01$, and ${ }^{* * *} p<0.001$.
A
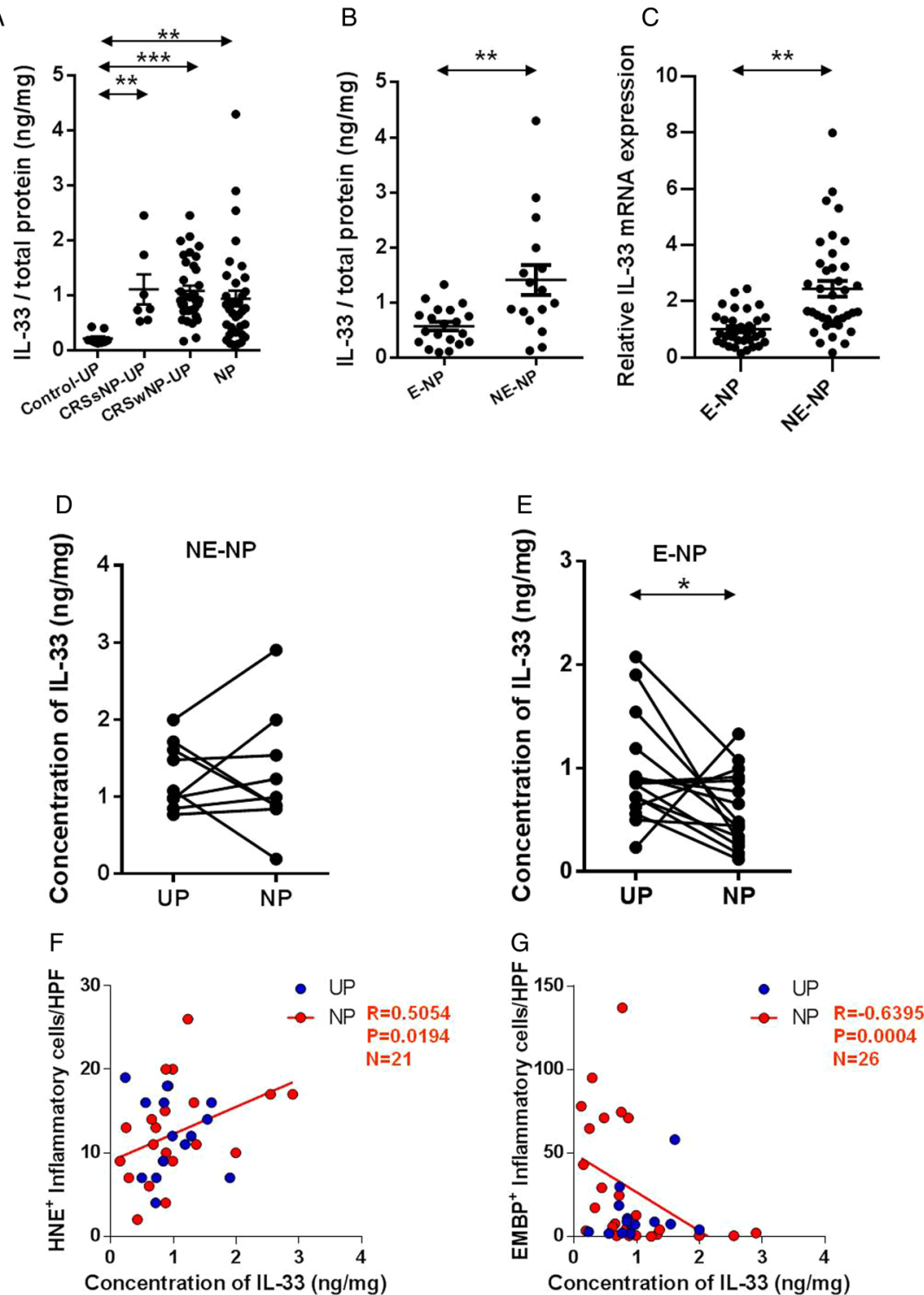
control type I error rates. Adjusted p values were presented in this text. The Wilcoxon matched-paired signed rank test was also used to compare the expression of IL-33 between UP and NP tissues in the same patients. The Spearman correlation test was used to determine bivariate relationships. The significance level was set at $\alpha$ value of 0.05 .
RESULTS

Expression of IL-33 and cellular origin in CRSwNP

To investigate expression of IL-33 in patients with CRSwNP, tissues were collected from patients with CRSsNP (UP tissue), patients with CRSwNP (NP and UP tissue) and control subjects (UP tissue). IL-33 protein levels were higher in UPs of CRSsNP

A
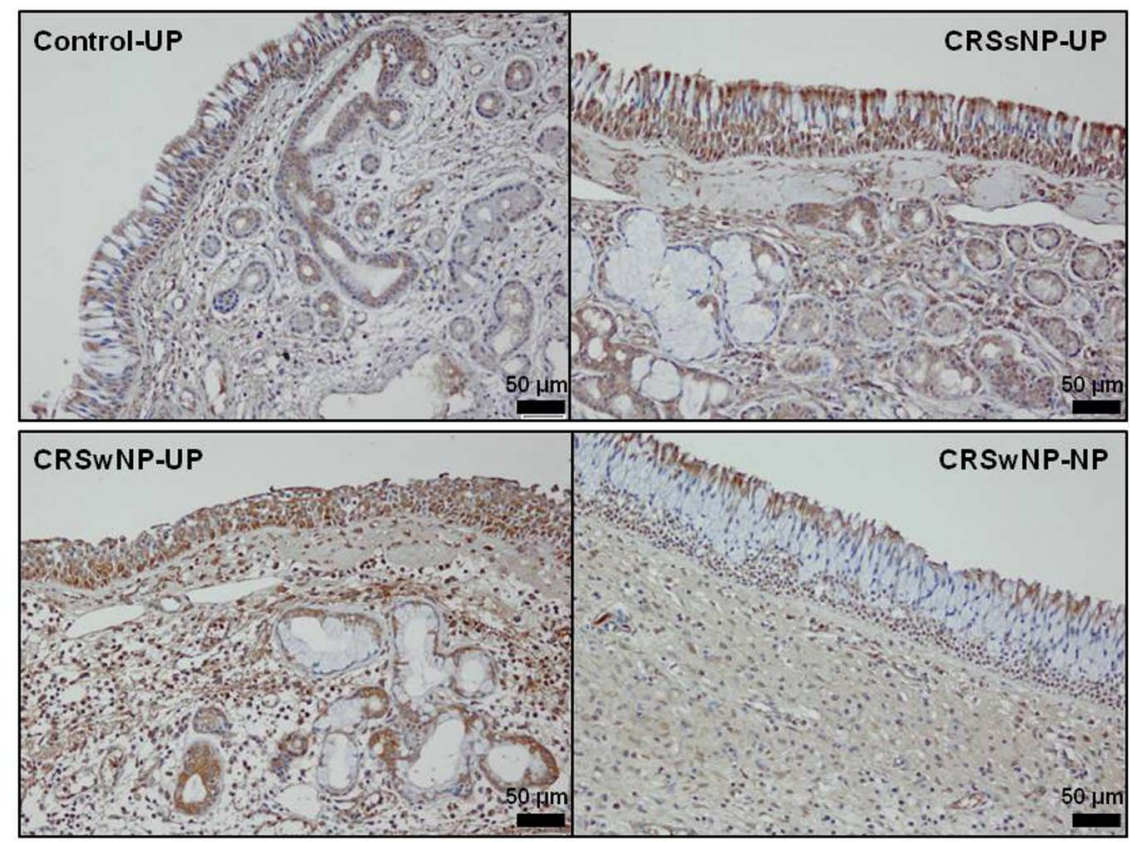

B
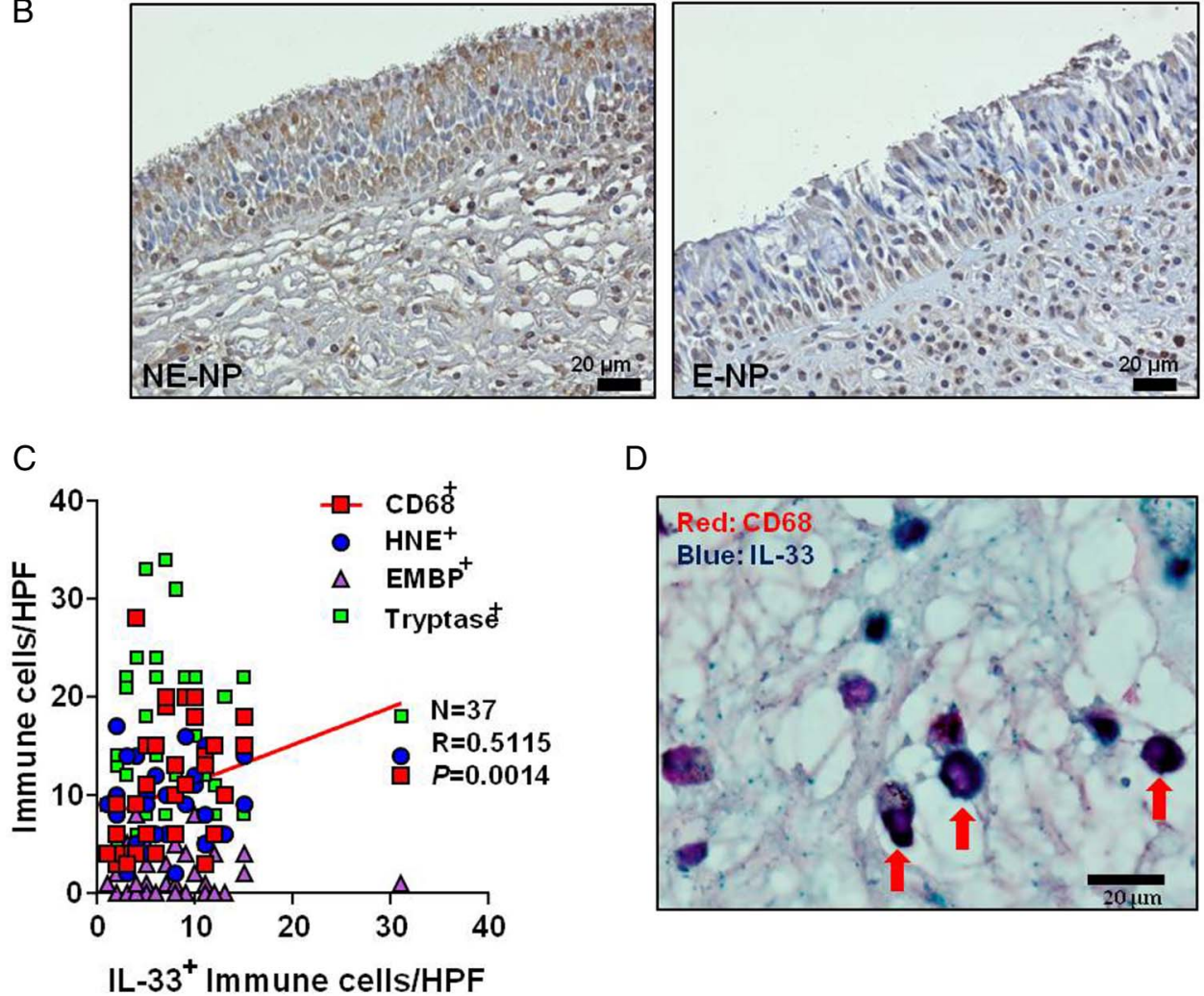

D

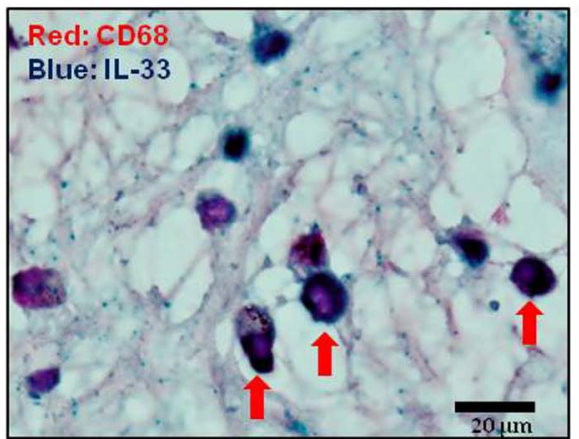

Figure 2 Expression of interleukin (IL)-33 in different types of chronic rhinosinusitis and its cellular origin. Immunohistochemistry detection of IL-33 was performed. (A) Representative immunostaining for IL-33 within the nasal polyp (NP) tissues and uncinate process (UP) tissues from control subjects, patients with chronic rhinosinusitis without nasal polyps (CRSSNP) and patients with chronic rhinosinusitis with nasal polyps (CRSwNP). (B) Representative immunostaining for IL-33 within the NP tissues from non-eosinophilic CRSwNP (NE-NP) and eosinophilic CRSwNP (E-NP). (C) Double immunohistochemical stain for CD68, HNE, EMBP, tryptase, and IL-33 was performed and double-positive cells were counted. Immunostaining of representative cells with CD68 (red) and IL-33 (blue) in NP tissue. Arrows indicate double-positive immune cells ( $\times 1000)$. HPF, high power field. 
(median: $0.760 \mathrm{ng} / \mathrm{mg}$ ), UPs of CRSwNP (median: $0.917 \mathrm{ng} / \mathrm{mg}$ ) and NPs (median: $0.772 \mathrm{ng} / \mathrm{mg}$ ) than in those of UPs (medians: $0.187 \mathrm{ng} / \mathrm{mg}$ ) in the controls (figure 1A). Interestingly, IL-33 protein levels were significantly increased in non-eosinophilic NP tissues (median: $1.112 \mathrm{ng} / \mathrm{mg}$ ) compared with those of eosinophilic NP (median: $0.616 \mathrm{ng} / \mathrm{mg}$; figure $1 \mathrm{~B}$ ). We also found that non-eosinophilic NP showed higher IL-33 mRNA levels than eosinophilic NP (2.53-fold, figure 1C). On the paired comparison of IL-33 protein levels between UPs and NPs from the same subjects, there was no significant difference in non-eosinophilic CRSwNP, whereas eosinophilic CRSwNP showed decreased concentration of IL-33 protein in NPs compared with UPs (figure 1D, E). Moreover, the concentration of IL-33 protein was positively correlated with the number of HNE-positive cells (neutrophils, $r=0.5054, p=0.0194$ ) and negatively associated with the number of EMBP-positive cells (eosinophils, $r=-0.6395$, $\mathrm{p}=0.004$ ) in NPs (figure $1 \mathrm{~F}, \mathrm{G}$ ).

Our IHC data confirmed that UP tissues from CRSsNP and CRSwNP, and NP tissues had increased expression of IL-33 compared with UP tissues from controls (figure $2 \mathrm{~A}$ and see online supplementary figure S2) and the expression of IL-33 was higher in epithelial cells of non-eosinophilic NPs versus those of eosinophilic NPs (figure 2B). To identify the cellular source of IL-33 in the subepithelial layer, IHC staining was performed using CD68 as a marker for macrophage, HNE for neutrophil, EMBP for eosinophil, and tryptase for mast cell. We observed a significant correlation between the number of IL-33-positive and CD68-positive cells in NPs $(r=0.5115$, $\mathrm{p}=0.0014$; figure 2C). IL-33-positive and CD68-positive cells in NPs were also observed on double IHC staining (figure 2D).

\section{Correlations between IL-33 expression and inflammatory markers in CRSwNP}

To elucidate the role of IL-33 in CRS, we first examined the relationship between IL-33 expression and various inflammatory markers in UPs and NPs from patients with CRSwNP. Protein levels of IFN- $\gamma(\mathrm{r}=0.6015, \mathrm{p}=0.0001)$ and IL-1 $\beta(\mathrm{r}=0.5022$, $\mathrm{p}=0.0018$ ) in NP tissues and IFN- $\gamma$, IL-1 $\beta$, TNF- $\alpha$, IL-17A and IL-22 levels in UP tissues were positively correlated with the concentrations of IL-33. However, these IL-33 levels were
Figure 3 Correlation between interleukin (IL)-33 expression and inflammatory markers in nasal tissues according to the different types of chronic rhinosinusitis. The correlation of protein expression between IL-33 and inflammatory markers: $(A)$ interferon (IFN)- $\gamma$, (B) IL-1 $\beta$, (C) tumour necrosis factor (TNF)- $\alpha$, (D) IL-17A, (E) IL-22 and (F) IL-5. NP, nasal polyp; UP, uncinate process.
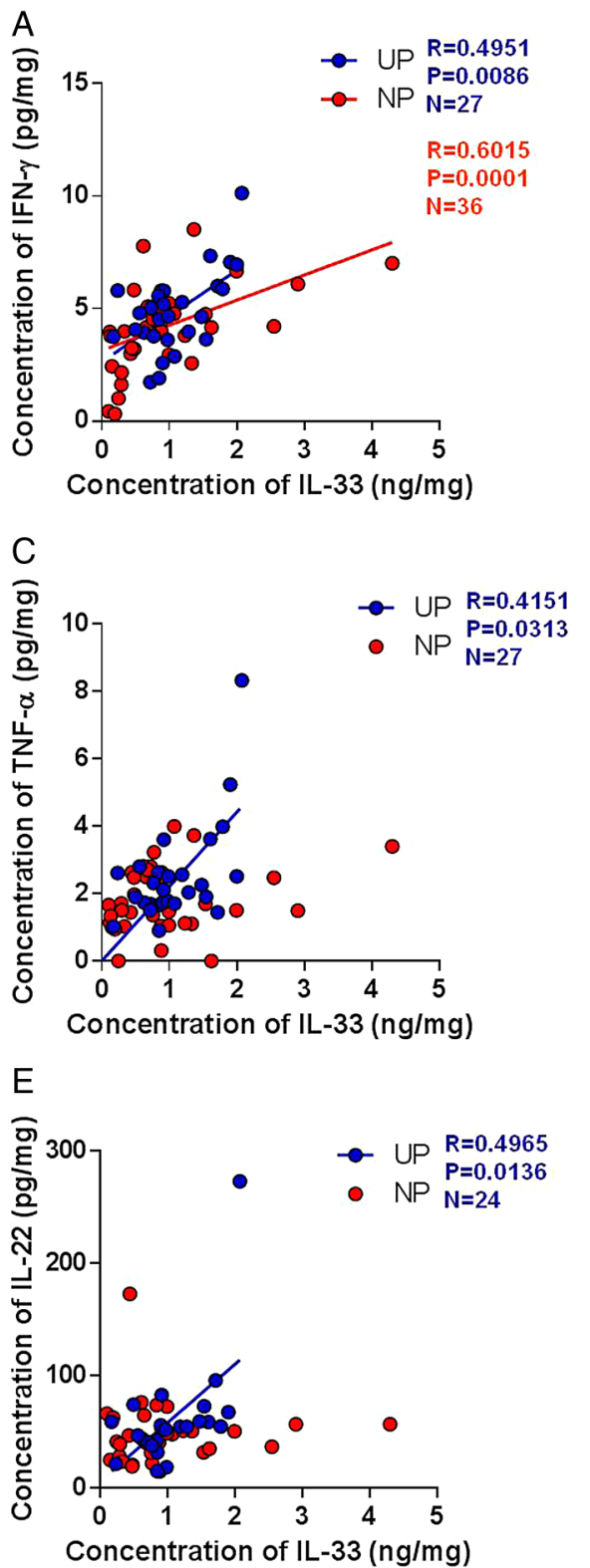
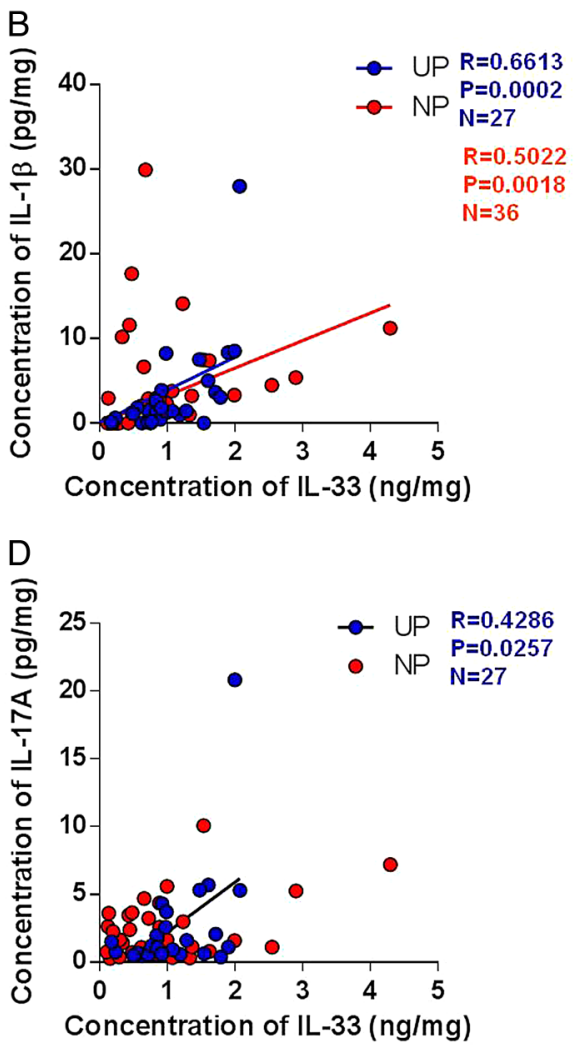

$\mathrm{F}$

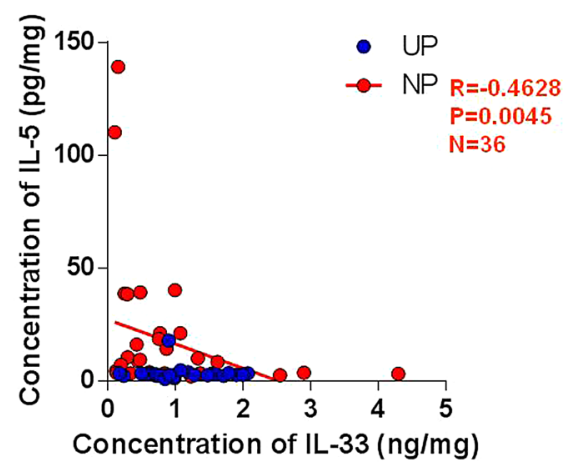


Figure 4 Correlation between interleukin (IL)-33 expression and recruitment markers for inflammatory cells in nasal tissues according to the different types of chronic rhinosinusitis. The correlation of protein expression between IL-33 and different markers: (A) MPO, (B) MCP4, (C) GRO $\alpha$, (D) nasal polyp; UP, uncinate process. GRO $\beta$, (E) CXCL8 and (F) ICAM-1. NP,
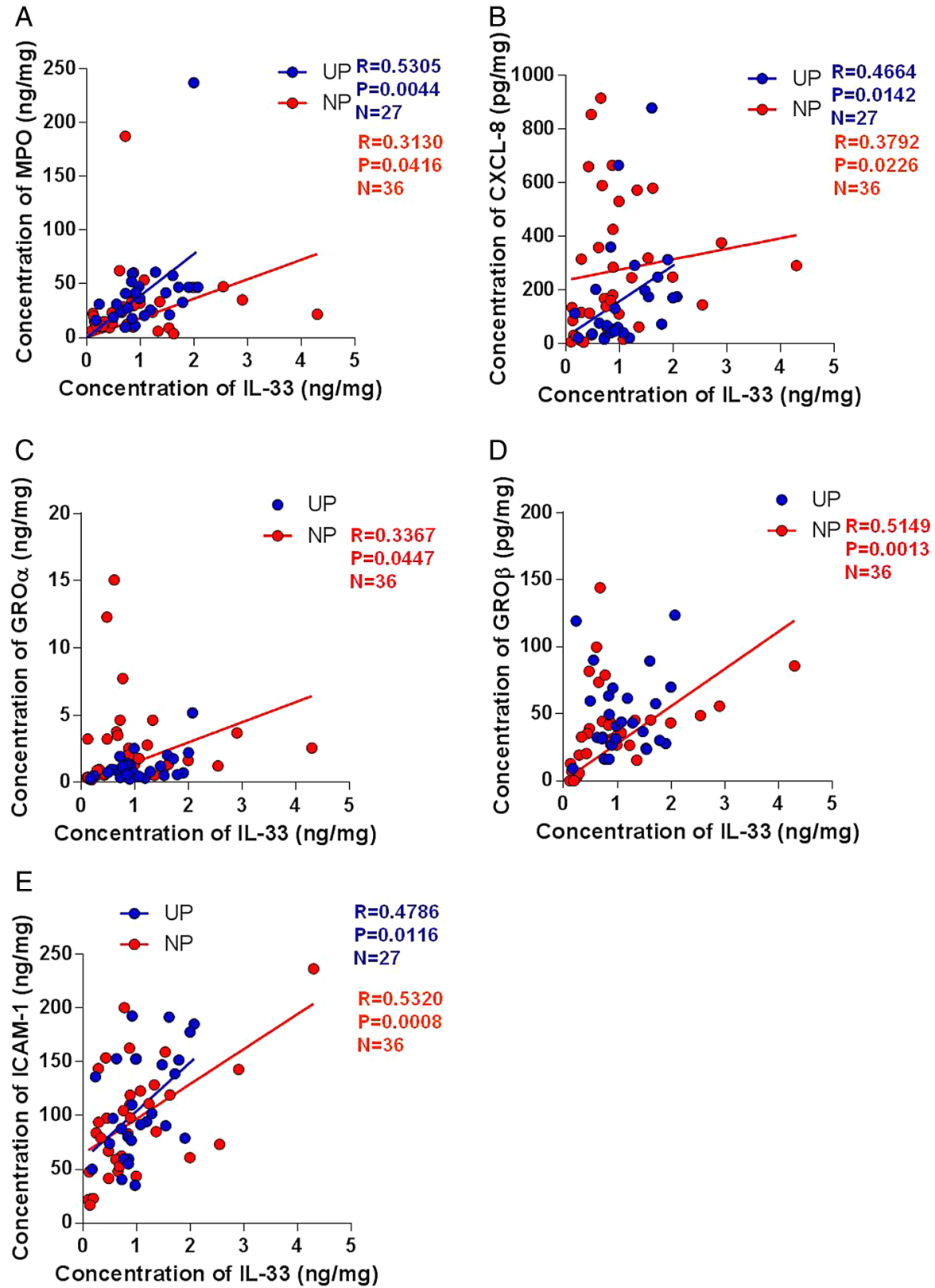

negatively correlated with IL-5 $(\mathrm{r}=-0.4628, \mathrm{p}=0.0045)$ protein levels in NP tissues (figure 3).

Second, to determine whether IL-33 was associated with recruitment of neutrophils, markers for human neutrophil (MPO), neutrophil-recruiting chemokines (CXCL-8, GRO- $\alpha$, GRO- $\beta$ ), and recruitment adhesion molecules (ICAM-1) were assessed in UPs and NPs from patients with CRSwNP. On the analysis of NP homogenate samples, the protein levels of MPO $(\mathrm{r}=0.3130, \quad \mathrm{p}=0.0416), \quad \mathrm{CXCL}-8 \quad(\mathrm{r}=0.3792, \mathrm{p}=0.0226)$, GRO- $\alpha(r=0.3367, p=0.0447)$, GRO- $\beta(r=0.5149, p=0.0013)$ and ICAM-1 $(\mathrm{r}=0.5320, \mathrm{p}=0.0008)$ were positively correlated with the concentrations of IL-33 protein (figure 4A-E). Moreover, in UP tissues from CRSwNP, the protein concentrations of IL-33 had a significant positive relationship with MPO, CXCL-8 and ICAM-1, respectively (figure 4A, B, E).

In this study, MMP-1 protein levels were significantly higher in tissue homogenates of eosinophilic NPs than those of controls, whereas increased production of MMP-2, MMP-9 and reduced levels of TIMP-1 were observed in tissue homogenates of non-eosinophilic NPs compared with controls (see online supplementary figure S3). Interestingly, we found that IL-33 protein levels were correlated with remodelling markers such as TIMP-1, MMP-2 and MMP-9 in NP tissues (figure 5A-C). The ratios of MMP-2/TIMP-1 and MMP-9/TIMP-1 were positively correlated with the concentrations of IL-33 protein in NP tissues (figure 5D, E).

\section{Anti-polyp effect of IL-33 neutralising antibody in a murine model of CRS}

To investigate the therapeutic potential of blocking the effects of IL-33 in CRSwNP, we used a murine model of CRS (figure 6A). IHC staining was performed to examine the expression and localisation of IL-33 in this model before examining the effects of treatment with an anti-mouse IL-33 antibody. This murine model showed higher expression of IL-33 in the epithelial layer and in inflammatory cells compared with the control mice (figure $6 \mathrm{~B}, \mathrm{C}$ ). In addition, the cytokine profiles of this murine model showed a mixed type of inflammatory response (see online supplementary figure S4) and were consistent with those of CRSwNP in Asian patients. ${ }^{6-8}$ The number of polypoid lesions, 
Figure 5 Correlation between interleukin (IL)-33 expression and remodelling markers in nasal tissues according to the different types of chronic rhinosinusitis. The correlation of protein expression between IL-33 and different markers: (A) tissue inhibitor of metalloproteinase (TIMP)-1, (B) matrix metalloproteinase (MMP)-2, (C) MMP-9, (D) MMP-2/TIMP-1 and (E) MMP-9/TIMP-1. NP, nasal polyp; UP, uncinate process.
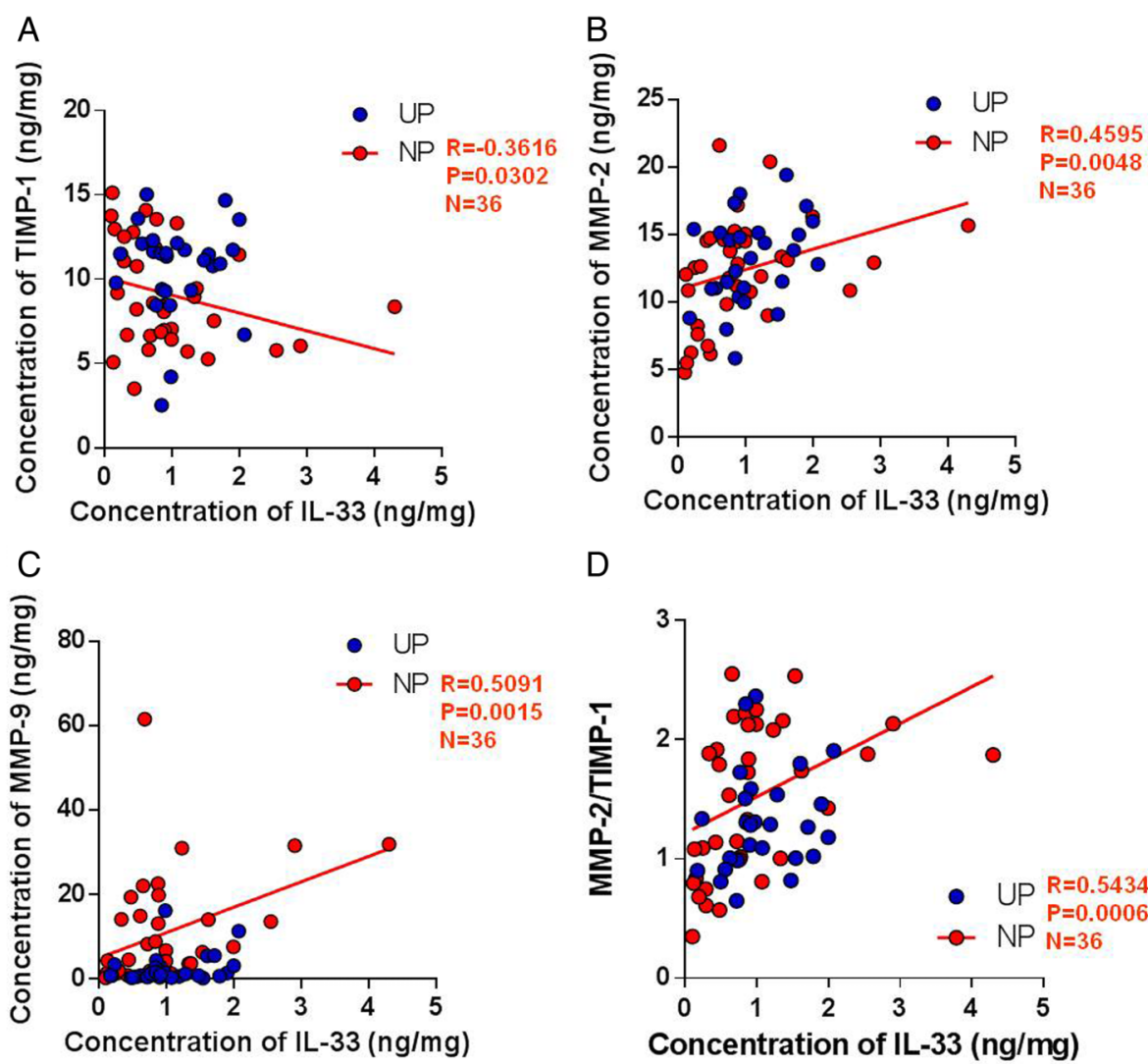

D

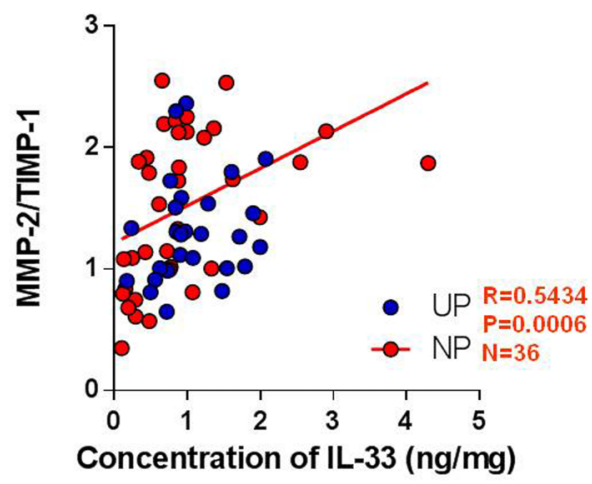

E

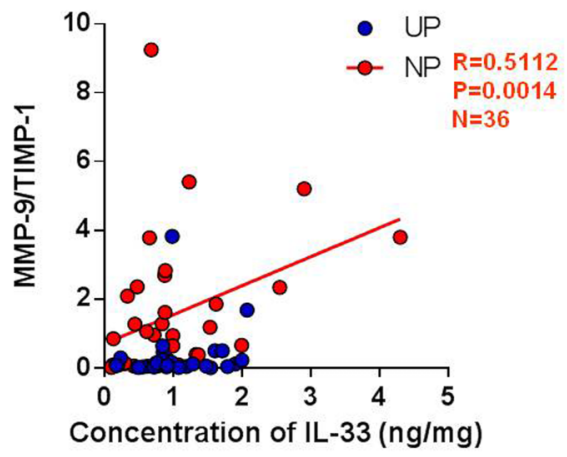

oedematous mucosal thickness, thickness of the subepithelial collagen layer, and number of goblet cells were apparently more severe in CRS mice than in control mice. Meanwhile, treatment with anti-IL-33 antibody (CRS $+\alpha$ IL-33 group) significantly reduced those findings in the CRS model (figure 7A-E and see online supplementary figure 5). Moreover, cytokine profiles of nasal lavage fluids from the anti-IL-33-treated mice were in accordance with histological findings (figure 7F-I). After treatment with anti-IL-33 antibody, protein levels of IFN- $\gamma$, IL-17A and TGF- $\beta 1$ were significantly decreased compared with those of CRS mice (without anti-IL-33). However, there were no statistical differences in IL-4 protein levels between CRS and CRS $+\alpha$ IL-33 groups.

\section{Changes in neutrophil recruitment after IL-33 inhibition}

To verify the change in cytokine profiles after IL-33 inhibition, we investigated the infiltration of inflammatory cells. The degree of neutrophilic infiltration in the CRS $+\alpha$ IL-33 group was decreased compared with that in the CRS group (figure 8A and see online supplementary figure 5A), whereas anti-IL-33 treatment had no inhibitory effect on the number of eosinophils in these mice (figure $8 \mathrm{~B}$ and see online supplementary figure $\mathrm{S} 6 \mathrm{~B}$ ). To verify that inflammatory cell recruitment was inhibited by anti-IL-33 treatment, semi-quantitative RT-PCR was used to assess the levels of recruitment adhesion molecules (ICAM-1 and vascular endothelial adhesion molecule (VCAM)-1), eosinophil chemotactic cytokines (CCL-11 and CCL-24), and neutrophil-recruiting chemokines (CXCL-1 and CXCL-2) in this experimental model (figure $8 \mathrm{C}-\mathrm{H}$ ). These adhesion molecules and chemokines were unregulated in CRS mice compared with controls, while anti-IL-33 treatment led to downregulation of ICAM-1, VCAM-1 and CXCL2 (figure 8C, D, H). However, there were no significant differences in CCL-11 and CCL-24 levels with or without anti-IL-33 treatment.

\section{DISCUSSION}

IL-33 is a nuclear cytokine from the IL-1 family constitutively expressed in airway epithelial cells. ${ }^{6}$ Although IL-33 is 
A

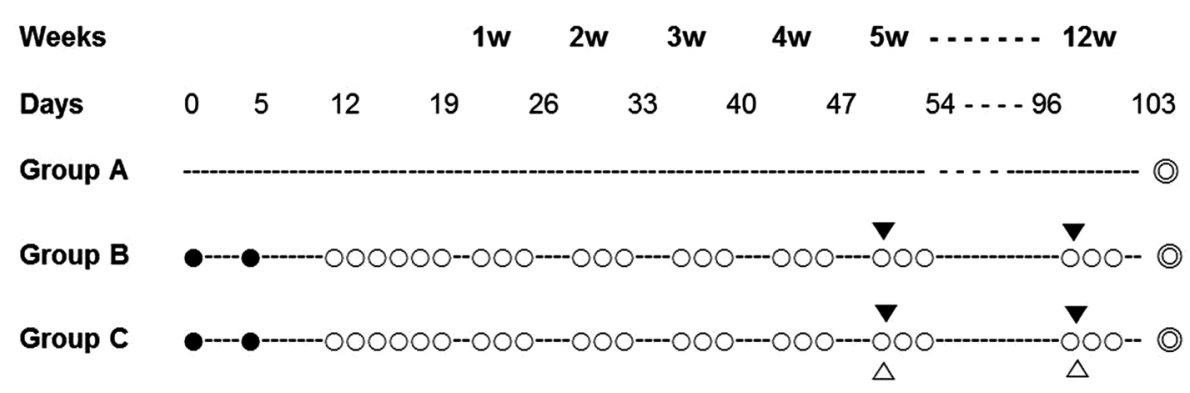

\section{: OVA+Alum sensitization $\quad$ O: intranasal OVA challenge \\ : intranasal SEB challenge $\triangle:$ Anti IL-33 (O): sacrifice}

B

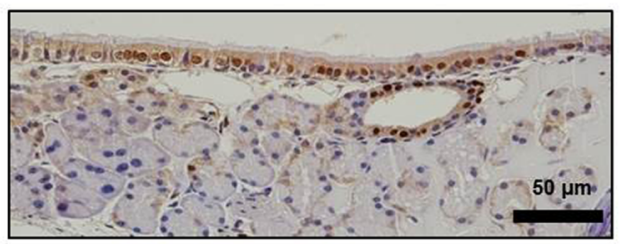

Control
C

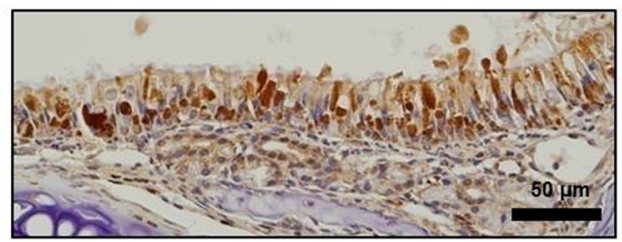

Chronic rhinosinusitis
with polypoid lesion model

Figure 6 Protocol and interleukin (IL)-33 expression of the murine model of chronic rhinosinusitis (CRS). (A) The protocol for generating the murine model of CRS is shown. Ovalbumin (OVA) and staphylococcal enterotoxin B (SEB) were administered into the nasal cavity to induce development of CRS. Anti-IL-33 (30 $\mu \mathrm{g}$ per mouse) was given intraperitoneally to investigate the effects of IL-33 blockade on nasal inflammation. The black circle indicates intraperitoneal injection for systemic sensitisation. The white circle denotes a week of daily intranasal instillation of phosphate-buffered saline (PBS) or OVA followed by 4 weeks of intranasal administration of PBS or OVA (three times per week). The black triangle indicates that SEB was administered intranasally once weekly during the last 8 weeks. The black arrow indicates anti-IL-33 antibody intraperitoneal injection. (B) IL-33 was weakly expressed in the nuclei of epithelial cells from PBS-treated mice, (C) while strong expression was observed in the nasal mucosa from the OVA/SEB-induced CRS model.

constitutively expressed in tissues under basal conditions, its expression can be further increased during inflammation. Thus, its biologically active form plays a role as an endogenous danger signal. ${ }^{30}$ In the present study, we investigated the role of IL-33 in the pathophysiology of CRSwNP in Asian subjects and also evaluated the therapeutic effect of anti-IL-33 using an animal CRS model. One recent study demonstrated that ILC2s were increased in patients with CRSwNP compared with those with CRSsNP. ${ }^{19}$ However, this study found no significant difference in IL-33 expression in ethmoidal mucosa between patients with CRSwNP and healthy controls. ${ }^{20}$ Meanwhile, there was a significant upregulation of ST2 expression in ethmoidal mucosa from patients with CRSwNP compared with the levels in healthy controls. Another recent study also reported that IL-33 expression was not significantly different between NP and healthy control tissues. ${ }^{19}$ Interestingly, we found a significant elevation of IL-33 protein levels in Asian patients with CRSwNP. In addition, our results showed elevated IL-33 protein levels in non-eosinophilic NPs compared with eosinophilic NPs. Moreover, analysis of the correlation between IL-33 and innate inflammatory cells indicates that IL-33 levels in NPs positively correlate with the number of HNE-positive cells (a marker for neutrophils) but negatively associate with the number of EMBP-positive cells (a marker for eosinophils).

Currently, it is thought that IL-33 produced by macrophages and dendritic cells is a potent activator of the innate immune system and acts on multiple targets, including mast cells, eosinophils, basophils, natural helper cells and NKT cells. A recent study showed that airway hyperreactivity (AHR), a typical feature of asthma, can be initiated by the activation of NKT cells, which induce alveolar macrophages to produce IL-33. ${ }^{31}$ In this study, the combination of NKT cells and alveolar macrophages plays an important role in the development of AHR. In agreement with these results, we observed that the number of CD68-positive cells has a significant correlation with the number of infiltrated inflammatory IL-33-positive cells and double IHC confirmed the expression of IL-33 in these CD68-positive macrophages. This suggests that CD68-positive cells (a marker for macrophage) may be an important cellular source of IL-33 during nasal polypogenesis. However, our study shows only the potential role of CD68-positive cells in nasal polypogenesis, and their exact role should be explored in future studies.

Furthermore, this study demonstrated that the concentration IL-33 levels correlated with Th1 and proinflammatory cytokines (IFN- $\gamma$ and IL-1 $\beta$ ) in NPs from patients with CRSwNP. Meanwhile, in UPs from patients with CRSwNP, the expression of Th17 or Th22 related cytokines (IL-17A, IL-22 and TNF- $\alpha$ ) was also positively correlated with IL-33. However, IL-5 and IL-33 protein levels were inversed correlated in NPs. In addition, our study demonstrated that there was a positive association between IL-33 and markers for recruitment of neutrophils, including MPO, neutrophilrecruiting chemokines (GRO- $\alpha$, GRO- $\beta$ and CXCL-8), and recruitment adhesion molecules (ICAM-1) in UPs and NPs 
Figure 7 Effect of anti-interleukin (IL)-33 on nasal inflammation in the murine model. (A) Number of polypoid lesions, (B) oedematous mucosal thickness, (C) subepithelial collagen deposition, and (D) the number of goblet cells were determined in 10 different high-power fields (HPF; $\times 400$ ) and compared among the groups $(n=5$ for control; $n=7$ for chronic rhinosinusitis (CRS); and $n=5$ for CRS $+\alpha$ lL-33). (E-H) Cytokine profiles from nasal lavage fluids were also compared among groups ( $n=8$ for each group). (I) Representative photograph for polypoid lesion in the control group (phosphate-buffered saline (PBS)), CRS model (POLYP), and CRS treated with anti-IL-33 (POLYP+olL-33). We performed the murine model three times $\left({ }^{*} p<0.05,{ }^{* *} p<0.01\right.$ and $* * * p<0.001)$. IFN, interferon; TGF, transforming growth factor.
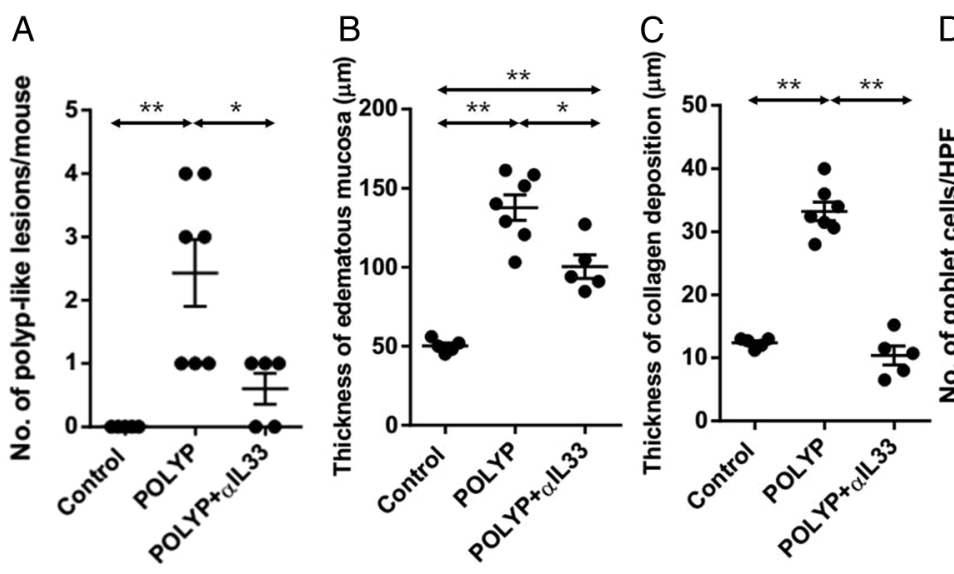

D

E

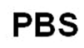

POLYP

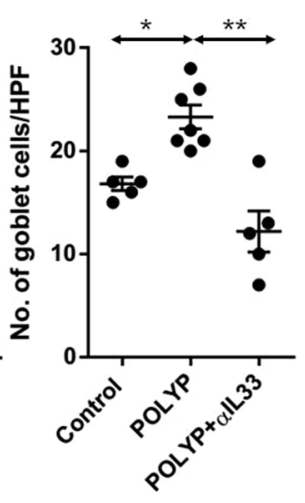

POLYP+aIL-33
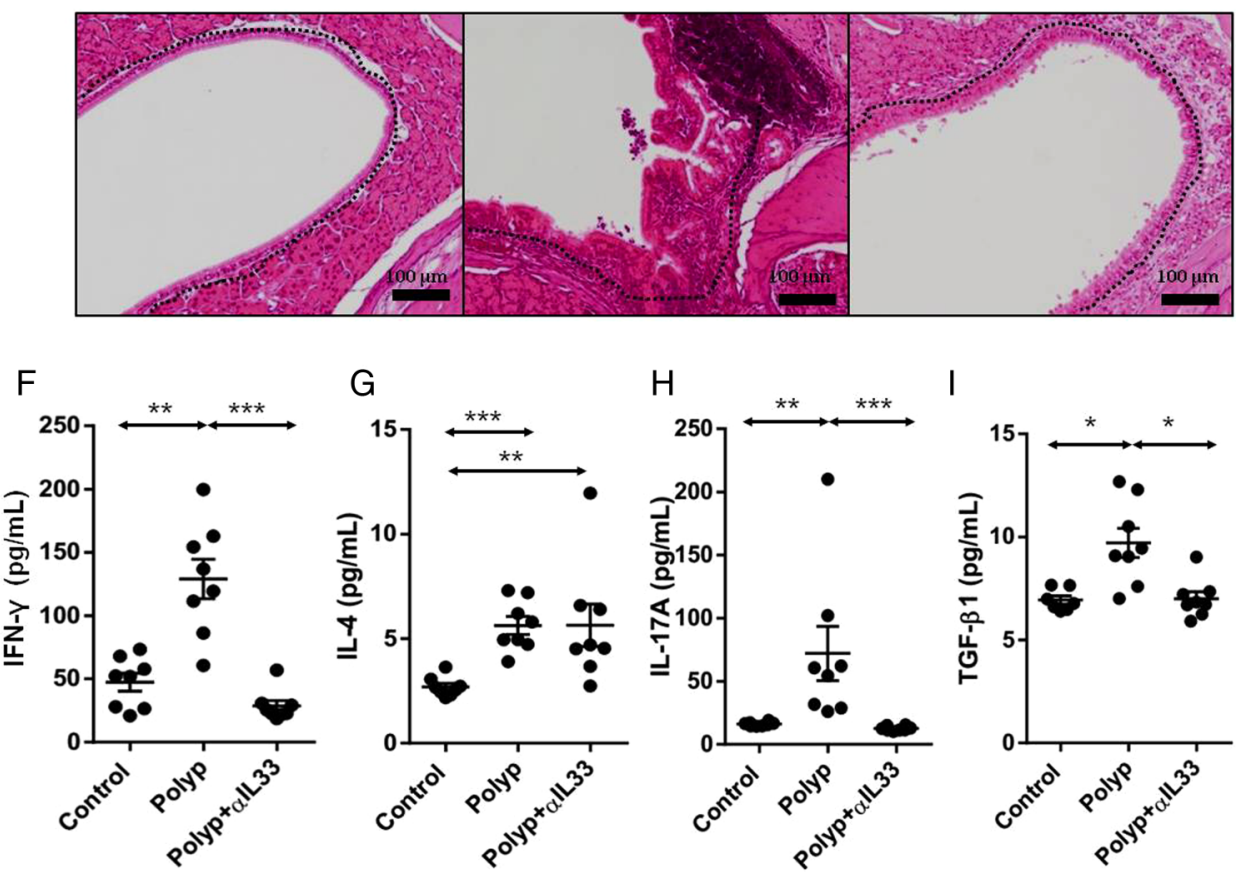

from CRSwNP. Other studies have reported a similar result regarding the association between IL-33 and neutrophils, ${ }^{8} 9$ implying that IL-33 may enhance neutrophil recruitment to sites of infection. The number of neutrophils in an allergeninduced murine model of allergic rhinitis and asthma was significantly decreased after anti-IL-33 treatment, ${ }^{32} 33$ whereas in a murine model for arthritis, neutrophil migration to the knee was induced by IL-33. ${ }^{13}$ Consistent with these studies, our results demonstrated that IL-33 was correlated with neutrophil recruitment.

The combination of MMPs, extracellular matrix (ECM) degrading enzymes, and TIMPs contributes to oedema formation in CRSwNP. During nasal polypogenesis, the balance between these proteases and protease inhibitors is important for degradation of ECM. ${ }^{34}{ }^{35}$ In this study, the concentrations of MMP-2 and MMP-9 protein were positively correlated with IL-33 levels in NPs. In addition, we found a negative correlation between TIMP-1 and IL-33 in NPs. Interestingly; a recent in vivo study revealed that MMP-2 and MMP-9 may promote neutrophil migration, ${ }^{36}$ which is consistent with our results.

We also utilised the murine model of CRS, ${ }^{25}$ and this model has been used to evaluate epithelial remodelling, the therapeutic benefits of certain treatment, and various immunological host characteristics. ${ }^{26-28}$ In this model, polypoid lesions are defined as distinct mucosal bulges with inflammatory cell infiltration with underlying microcavity formation. This animal model showed mixed inflammation (see online supplementary figure S2) involving both eosinophilic and neutrophilic activity, which is consistent with NPs with mixed inflammation. Thus, the animal model using ovalbumin (OVA)/ staphylococcal enterotoxin B (SEB) was well suited to determine whether anti-IL-33 antibody exerted a therapeutic effect on chronic inflammation and NP formation. While mice treated with anti-IL-33 showed reduced eosinophilic inflammation in OVA-induced acute allergic airway diseases, ${ }^{32} 33$ the effect of IL-33 blockade on chronic sinonasal inflammation remains unknown. In this study, we found increased production of IL-33 in epithelial and inflammatory cells in OVA/SEB-induced CRS mice. These findings suggest that IL-33 may contribute to OVA/SEB-induced sinonasal inflammation. In addition, we found that the degree of average mucosal thickness was diminished by administration of anti-IL-33. Similarly, the CRS $+\alpha$ IL-33 group showed a significant decrease in the thickness of the subepithelial collagen and in the number of goblet cells 
Figure 8 Anti-IL-33 therapy suppresses neutrophil infiltration, expression of neutrophil chemotactic cytokines and intercellular adhesion molecules in a murine model. $(A)$ The numbers of infiltrated neutrophils and (B) infiltrated eosinophils were counted from 10 different high-power fields (HPF; $\times 400)$ and compared among groups ( $n=5$ for control, $n=7$ for chronic rhinosinusitis (CRS), and $n=5$ for CRS $+\alpha$ IL-33). Relative mRNA expression levels of the intercellular and vascular adhesion molecules (C) ICAM-1 and (D) VCAM-1, the eosinophil-recruiting chemokines (E) CCL11 and (F) CCL24, and the neutrophil-recruiting chemokines $(\mathrm{G})$ CXCL1 and (H) CXCL2 were compared among groups ( $n=5$ for all groups). We performed the murine model three times. $\left({ }^{*} p<0.05,{ }^{* *} p<0.01\right.$ and $\left.{ }^{* * *} p<0.001\right)$.
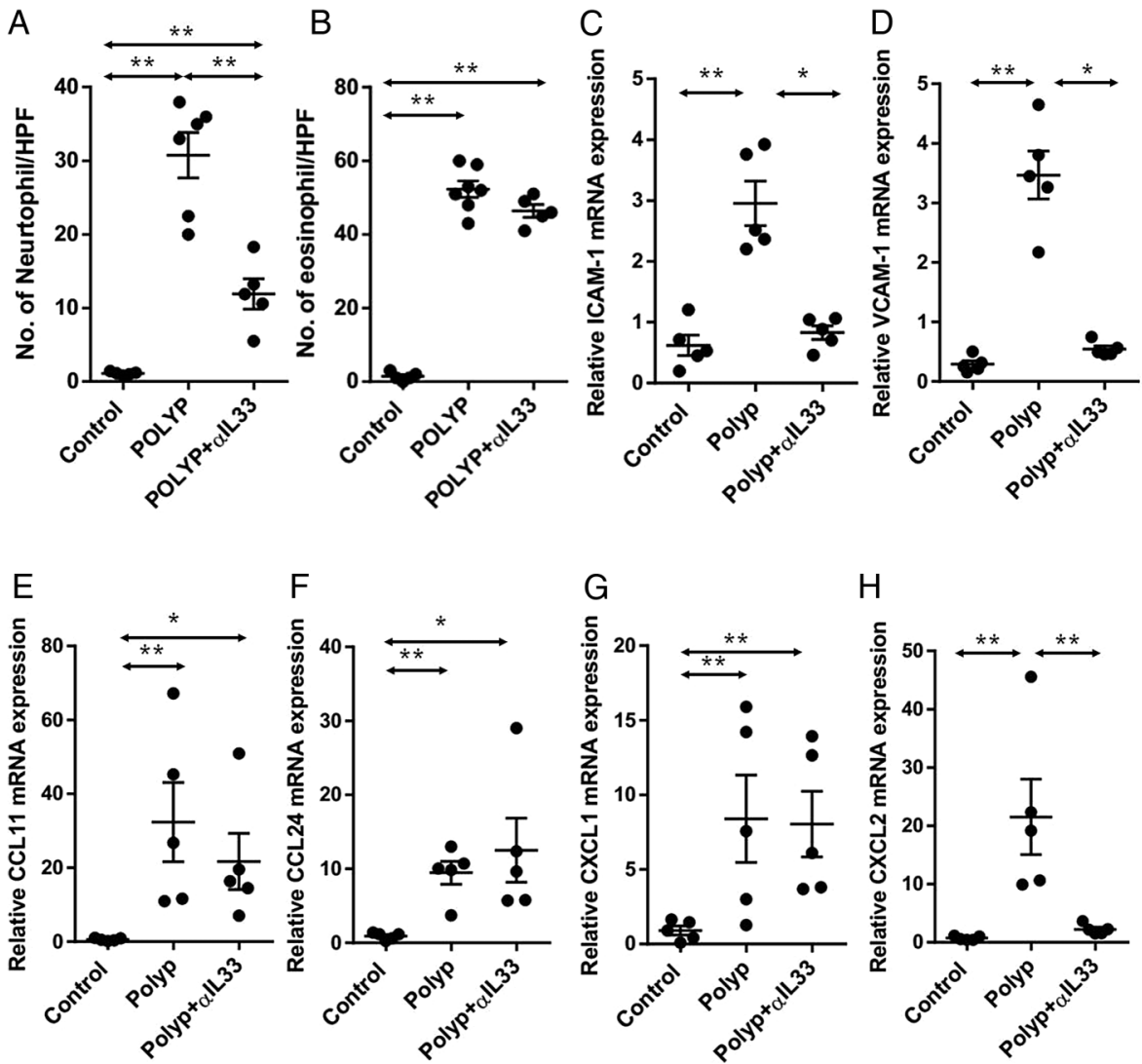

compared with the CRS group. Interestingly, in our animal study, we observed that the infiltration of neutrophils was decreased in the CRS $+\alpha$ IL-33 group compared with the CRS group. However, no significant differences in eosinophilic infiltration were observed between these groups. Moreover, we demonstrated decreased expression of cytokines (IFN- $\gamma / \mathrm{IL}-17 \mathrm{~A} /$ TGF- $\beta 1$ ), adhesion molecules (ICAM-1/VCAM-1), and neutrophil-recruiting chemokine (CXCL2) with anti-IL-33 treatment. These cytokines, adhesion molecules and chemokines are closely related to neutrophil recruitment. Considering these results, we speculate that the anti-inflammatory effect of anti-IL-33 antibody may stem from suppression of neutrophil recruitment. However, the exact subset(s) of IL-33-responsive innate immune cells involved in reducing neutrophil recruitment should be further investigated.

In conclusion, we found that UP or non-eosinophilic NP tissues of CRSwNP were characterised by elevated expression of IL-33, and these levels correlated with levels of Th1/Th17 cytokines. Additionally, IL-33 protein levels were associated with various markers for neutrophil recruitment and remodelling in NP tissues. Moreover, anti-IL-33 antibody exerted an inhibitory effect on chronic sinonasal inflammation by reducing the recruitment of neutrophils in a murine model of CRS. These findings suggest that IL-33 plays a crucial role in the pathogenesis of neutrophilic inflammation in patients with CRS and that IL-33 inhibition may provide a new treatment strategy for CRS, particularly in non-eosinophilic NPs.

Contributors Study supervision: DWK. Critical revision of the manuscript for important intellectual content: D-KK, HRJ and KME. Conceived and designed the experiments: D-KK and DWK. Performed the experiments and analysed the data:
D-KK, J-HM, SHC, SO and DWK. Contributed reagents/materials/analysis tools and wrote the paper: D-KK, DC and DWK.

Funding This research was supported by a clinical research grant-in-aid from the Seoul Metropolitan Government Seoul National University (SMG-SNU) Boramae Medical Center (03-2013-7), by SK Telecom Research Fund (01-2014-10).

Competing interests None declared.

Patient consent Obtained.

Ethics approval This study was approved by the institutional review board of Seoul National University (Boramae Medical Center).

Provenance and peer review Not commissioned; externally peer reviewed.

\section{REFERENCES}

1 Moussion C, Ortega N, Girard JP. The IL-1-like cytokine IL-33 is constitutively expressed in the nucleus of endothelial cells and epithelial cells in vivo: a novel 'alarmin'? PLOS ONE 2008;3:e3331.

2 Pichery M, Mirey E, Mercier $\mathrm{P}$, et al. Endogenous IL-33 is highly expressed in mouse epithelial barrier tissues, lymphoid organs, brain, embryos, and inflamed tissues: in situ analysis using a novel II-33-LacZ gene trap reporter strain. J Immunol 2012;188:3488-95.

3 Schmitz J, Owyang A, Oldham E, et al. IL-33, an interleukin-1-like cytokine that signals via the IL-1 receptor-related protein ST2 and induces T helper type 2-associated cytokines. Immunity 2005;23:479-90.

4 Lüthi AU, Cullen SP, McNeela EA, et al. Suppression of interleukin-33 bioactivity through proteolysis by apoptotic caspases. Immunity 2009;31:84-98.

5 Talabot-Ayer D, Lamacchia C, Gabay C, et al. Interleukin-33 is biologically active independently of caspase-1 cleavage. J Biol Chem 2009;284:19420-6.

6 Cayrol C, Girard JP. IL-33: an alarmin cytokine with crucial roles in innate immunity, inflammation and allergy. Curr Opin Immunol 2014;31:31-7.

7 Nakae S, Morita H, Ohno T, et al. Role of interleukin-33 in innate-type immune cells in allergy. Allergol Int 2013;62:13-20.

8 Hueber AJ, Alves-Filho JC, Asquith DL, et al. IL-33 induces skin inflammation with mast cell and neutrophil activation. Eur J Immunol 2011;41:2229-37.

9 Alves-Filho JC, Sônego F, Souto FO, et al. Interleukin-33 attenuates sepsis by enhancing neutrophil influx to the site of infection. Nat Med 2010;16: 708-12. 
10 Kurowska-Stolarska M, Stolarski B, Kewin P, et al. IL-33 amplifies the polarization of alternatively activated macrophages that contribute to airway inflammation. J Immunol 2009;183:6469-77.

11 Espinassous Q, Garcia-de-Paco E, Garcia-Verdugo I, et al. IL-33 enhances lipopolysaccharide-induced inflammatory cytokine production from mouse macrophages by regulating lipopolysaccharide receptor complex. J Immunol 2009;183:1446-55.

$12 \mathrm{Xu} \mathrm{D}$, Jiang HR, Kewin P, et al. IL-33 exacerbates antigen-induced arthritis by activating mast cells. Proc Natl Acad Sci USA 2008;105:10913-18.

13 Verri WA Jr, Souto FO, Vieira SM, et al. IL-33 induces neutrophil migration in rheumatoid arthritis and is a target of anti-TNF therapy. Ann Rheum Dis 2010;69:1697-703.

14 Talabot-Ayer D, McKee T, Gindre P, et al. Distinct serum and synovial fluid interleukin (IL)-33 levels in rheumatoid arthritis, psoriatic arthritis and osteoarthritis. Joint Bone Spine 2012;79:32-7.

15 Cho YS, Choi SH, Park KH, et al. Prevalence of otolaryngologic diseases in South Korea: data from the Korea national health and nutrition examination survey 2008. Clin Exp Otorhinolaryngol 2010;3:183-93.

16 Van Cauwenberge P, Watelet JB. Epidemiology of chronic rhinosinusitis. Thorax 2000;55(Suppl 2):S20-1.

17 Fokkens WJ, Lund VJ, Mullol J, et al. EPOS 2012: European position paper on rhinosinusitis and nasal polyps 2012. A summary for otorhinolaryngologists. Rhinology 2012;50:1-12.

18 Huvenne W, van Bruaene N, Zhang N, et al. Chronic rhinosinusitis with and without nasal polyp: what is the difference? Curr Allergy Asthma Rep 2009;9:213-20.

19 Baba S, Kondo K, Kanaya K, et al. Expression of IL-33 and its receptor ST2 in chronic rhinosinusitis with nasal polyps. Laryngoscope 2014;124:E115-22.

20 Shaw JL, Fakhri S, Citardi MJ, et al. IL-33-responsive innate lymphoid cells are an important source of IL-13 in chronic rhinosinusitis with nasal polyps. Am J Respir Crit Care Med 2013;188:432-9.

21 Reh DD, Wang Y, Ramanathan M, Jr., et al. Treatment-recalcitrant chronic rhinosinusitis with polyps is associated with altered epithelial cell expression of interleukin-33. Am J Rhinol Allergy 2010;24:105-9.

22 Nagarkar DR, Poposki JA, Tan BK, et al. Thymic stromal lymphopoietin activity is increased in nasal polyps of patients with chronic rhinosinusitis. J Allergy Clin Immunol 2013;132:593-600.e512.

23 Diaz-Vazquez C, Torregrosa-Bertet MJ, Carvajal-Uruena I, et al. Accuracy of ImmunoCAP Rapid in the diagnosis of allergic sensitization in children between 1 and 14 years with recurrent wheezing: the IReNE study. Pediatr Allergy Immunol 2009;20:601-9.

24 Kim DK, Park MH, Chang DY, et al. MBP-positive and CD11c-positive cells are associated with different phenotypes of Korean patients with non-asthmatic chronic rhinosinusitis. PLOS ONE 2014;9:e111352.

25 Kim DW, Khalmuratova R, Hur DG, et al. Staphylococcus aureus enterotoxin B contributes to induction of nasal polypoid lesions in an allergic rhinosinusitis murine model. Am J Rhinol Allergy 2011;25:e255-61.

26 Shin HW, Cho K, Kim DW, et al. Hypoxia-inducible factor 1 mediates nasal polypogenesis by inducing epithelial-to-mesenchymal transition. Am J Respir Crit Care Med 2012;185:944-54.

27 Kim SW, Kim DW, Khalmuratova R, et al. Resveratrol prevents development of eosinophilic rhinosinusitis with nasal polyps in a mouse model. Allergy 2013;68:862-9.

28 Shin HW, Kim DK, Park MH, et al. IL-25 as a novel therapeutic target in nasal polyps of patients with chronic rhinosinusitis. J Allergy Clin Immunol 2015;135:1476-85 e1477.

29 Rhee CS, Libet L, Chisholm D, et al. Allergen-independent immunostimulatory sequence oligodeoxynucleotide therapy attenuates experimental allergic rhinitis. Immunology 2004;113:106-13.

30 Miller AM. Role of IL-33 in inflammation and disease. J Inflamm (Lond) 2011;8:22.

31 Chang YJ, Kim HY, Albacker LA, et al. Innate lymphoid cells mediate influenza-induced airway hyper-reactivity independently of adaptive immunity. Nat Imunol 2011;12:631-8.

32 Kim YH, Yang TY, Park CS, et al. Anti-IL-33 antibody has a therapeutic effect in a murine model of allergic rhinitis. Allergy 2012;67:183-90.

33 Liu X, Li M, Wu Y, et al. Anti-IL-33 antibody treatment inhibits airway inflammation in a murine model of allergic asthma. Biochem Biophys Res Commun 2009;386:181-5.

34 Li X, Meng J, Qiao X, et al. Expression of TGF, matrix metalloproteinases, and tissue inhibitors in Chinese chronic rhinosinusitis. J Allergy Clin Immunol 2010;125:1061-8.

35 Watelet JB, Bachert C, Claeys C, et al. Matrix metalloproteinases MMP-7, MMP-9 and their tissue inhibitor TIMP-1: expression in chronic sinusitis vs nasal polyposis. Allergy 2004;59:54-60.

36 Song J, Wu C, Zhang $X$, et al. In vivo processing of CXCL5 (LIX) by matrix metalloproteinase (MMP)-2 and MMP-9 promotes early neutrophil recruitment in IL-1 $\beta$-induced peritonitis. J Immunol 2013;190:401-10. 